\title{
Experiments in Everyday Mobility : Social Dynamics of Achieving a Sustainable Lifestyle
}

\section{Laakso, Senja}

2019-06

Laakso , S 2019 , ' Experiments in Everyday Mobility : Social Dynamics of Achieving a

Sustainable Lifestyle ' , Sociological Research Online , vol. 24 , no. 2 , pp. 235-250 . https://doi.org/10.1177/1360780

http://hdl.handle.net/10138/307114

https://doi.org/10.1177/1360780418823222

acceptedVersion

Downloaded from Helda, University of Helsinki institutional repository.

This is an electronic reprint of the original article.

This reprint may differ from the original in pagination and typographic detail.

Please cite the original version. 


\title{
Experiments in everyday mobility: Social dynamics of achieving a sustainable lifestyle
}

Senja Laakso

Centre for Consumer Society Research

P.O. Box 24 (Unioninkatu 40), 00014 University of Helsinki, Finland

senja.1aakso@helsinki.fi

\begin{abstract}
This article presents the results from an experimental project in Jyväskylä, Finland in which five 'pioneer households' aimed to reduce their environmental impacts by a variety of trials in different domains of daily consumption. The article analyses this 'home lab' experiment from a practicetheoretical perspective, focusing particularly on everyday mobility and the social interplay that occurs in mobility practices in different contexts. In so doing, the article explores the reasons behind the various outcomes of experimentation and discusses the potential of such experimentation to facilitate transformation in mobility practices. The results suggest that in order to shift daily mobility onto a more sustainable path, the social dynamics related to mobility practices should be better addressed. For example, the negotiations both inside and outside the participating households proved important in challenging the ways of doing mobility. Moreover, the potential for the diffusion of alternative mobility practices was shown to depend on a variety of factors that maintained the normality and acceptability of private driving. Utilising practice-theoretical insights in living laboratories can open new areas for experimentation and facilitate understanding of the shift in everyday practices towards greater sustainability.
\end{abstract}

\section{Keywords}

Daily mobility, social practice theory, social dynamics, experiments, home labs 


\section{Introduction}

Cities and municipalities around the world are struggling with unsustainable everyday mobility and 'car cultures' nurturing the idea of the car as the default option for daily mobility (Sheller 2012; Urry 2004). Current mainstream behavioural and technological approaches to shift this development, such as providing people with incentives to use public transport or buy an electric car (see Hesselgren et al. 2015; Skarin et al. 2017; Thøgersen and Møller 2008), have been insufficient. These approaches also easily trivialise the ways car use has been legitimised, normalised and stabilised in everyday life as well as the complex interactions that maintain mobility practices (Sheller 2012; Shove and Walker 2010; Urry 2004).

In recent years, experimentation has been adopted as a means to find new ways to steer consumption in a more sustainable direction (Bulkeley and Castán Broto 2013; Heiskanen et al. 2015; 2017; Hoffmann 2011; Laakso et al. 2017). In this regard, small initiatives and experiments that encourage the participation of various stakeholders and raise general knowledge on the issue in question have proved valuable (Irvine and Kaplan 2001). As part of this development, a growing number of 'home lab' and 'pioneer household' projects are being deployed (e.g. Hargreaves et al. 2015; Devaney and Davies 2016). In these projects, participants' homes are seen as 'living laboratories' in which researchers, family members and other stakeholders (such as NGOs and companies) collaborate in innovation processes in real-world settings (Bergvall-Kåreborn et al. 2009).

In Finland, for instance, a variety of projects have employed the idea of recruiting a small number of households to act as examples of more sustainable everyday life. Such projects have involved 30 'climate families' in Tampere, six families performing 'climate exercises' in Helsinki and Vantaa and five households spending a 'carbon-free April' in Joensuu. ${ }^{1}$ Similar projects can be found, for example, in Sweden and Denmark (see Ahonen 2011; Hesselgren and Hasselqvist 2016). In these projects, measurable outcomes (such as reductions in carbon emissions) and publicity have been important. Nevertheless, while participant and other stakeholder experiences could be useful for analysing the changes in everyday practices and for investigating the potential of novel practices to diffuse into new contexts, this kind of research has remained rare (Ahonen 2011; Laakso 2017a; Papazu 2015).

${ }^{1}$ See ilmankos.fi/ilmastoperheet; ilmastokatu.fi/ilmastotreeni; joensuu.fi/vahahiilinen-huhtikuu. 
By utilising the approach of social practice theory (SPT), the article aims to capture the experiences and social interplay of these 'pioneering households' within the contexts in which they perform everyday practices, and thus to illustrate the role social dynamics play in experimentation and its outcomes. The article suggests that a better understanding of these dynamics might present the opportunities that Evans et al (2012: 115) consider necessary to "to re-think and re-frame the entry points, scope and orientations of policy initiatives" in governing sustainable consumption.

The article presents the results of a home lab experiment in Jyväskylä, Finland. In the project, five households aimed to reduce their natural-resource use to a more sustainable level by a variety of trials. The experiment was intended to act as an encouraging example; as the results demonstrate, a more sustainable level of consumption could be achieved with relatively few changes in everyday life (Laakso and Lettenmeier 2016). However, when the experiment is analysed through 'practice lenses', these changes are less straightforward than the environmental indicators might suggest; rather, they reflect the complex organisation of everyday life.

The article takes daily mobility as the starting point of the analysis and illustrates how mobility practices - routinised behaviours consisting of several interconnected elements (Reckwitz 2002) are connected to surrounding practices and thus to the different social contexts within which these practices are performed. Mobility is the focus of the study for two reasons. First, it combines many practices, such as working, shopping and engaging in leisure time activities. This means that mobility is performed in a network comprised of different contexts, and thus better understanding is required of the significance of factors such as social dynamics, interplay and normality in these different contexts (Aro 2016; Cairns et al. 2014). Second, although mobility plays an important role in the transition towards sustainability, efforts so far have mainly overlooked its embeddedness in daily life (Shove and Walker 2007; Watson 2012). Given the limited success of many behavioural interventions aimed at reducing car use (Arnott et al. 2014; Graham-Rowe et al. 2011), there is a need for in-depth understanding of the reasons behind the stability of mobility practices, especially those practices beyond the act of driving.

The following sections outline the practice-theoretical background of the study and the materials and methods used. The last two sections then present the results and discuss the conclusions of the study. 


\section{Using practice-theoretical insights to experiment with sustainable mobility}

Social practice theory (SPT) has been widely used to understand the embeddedness of mobility practices in everyday life (see Heisserer and Rau 2015) and to explore ways of moving 'beyond automobility' (e.g. Birtchnell 2012; Watson 2012). This research covers areas such as commuting (e.g. Heisserer and Rau 2015), leisure travelling (Hui 2012; 2013), food shopping (Mattioli and Anable 2017) and car-sharing (Kent and Dowling 2013). Furthermore, a practice-theoretical framework has also been used to provide conceptualisations of policy interventions that seek to shift patterns of mobility (Spurling et al. 2013; Spurling and McMeekin 2015).

A widely shared notion of practices is that they comprise configurations of elements, such as shared meanings, norms and rules, knowledge and competences, and materials, technologies and infrastructure (Gram-Hanssen 2011; Shove et al. 2012). SPT steers attention away from individual elements towards constellations and combinations of elements and how shared elements connect practices (Bellotti and Mora 2016; Gram-Hanssen 2011; Shove et al. 2012). Due to the interdependent nature of practices, it can be challenging to specify what exactly constitutes a practice, and identifying individual practices, or even 'bundles of practices', in particular domains of everyday life is rarely unambiguous. Warde (2005) uses the concept of integrative practices to illustrate how the practice of driving, for example, includes many other (dispersed) practices, such as following rules and communicating with other people. Driving, in turn, is part of many other practices. For example, Sheller (2012: 183) distinguishes subaltern practices such as driving and cycling from the mainstream, legitimised practices of socialising and commuting to work and the wider background quotidian practices determining the 'car cultures'. Thus, in considering the embeddedness of mobility in everyday life, the focus should be on the ways in which the forms and modes of mobility, such as car driving, allow other socially valued practices, such as travelling to work or visiting friends, to be accomplished (Cass and Faulconbridge 2016; Heisserer and Rau 2015; Shove et al. 2015).

Practices can be perceived as both entities and performances. Practices-as-entities are formed as a collective achievement and capture the underlying organisational principles or linkages that shape the actions that make up the practice (Heisserer and Rau 2015). By contrast, practices-as-performances can be conceptualised as the product of rather stable social practices that are reproduced over time and across locales and scales. Performers of practice can nevertheless "adapt, improvise, and experiment" with ways of doing, thus transforming the practice (Warde 2005: 141). Practices 
commonly progress through phases in which they are initiated by innovations, percolate through a community of practitioners and are differentiated in various performances (Bellotti and Mora 2016; Shove et al. 2012). The collective organisation of a practice, however, determines whether certain actions are deemed correct, appropriate or important (in certain situations) and how these actions follow one another (Aro 2016; Heisserer and Rau 2015). The distinction between practices-asperformances and practices-as-entities is also essential for understanding how sustainable performances become mainstream: the new reconfiguration must recruit more and more individuals to become a generally recognised entity.

Within experimentation such as living labs, attention should thus be paid to the ways practices are connected to other practices (see also Spurling et al. 2013), as well as to the alliances and conflicts within and among 'complexes of practices' (Halkier and Jensen 2011; Hargreaves 2011). New ways of performing the practice may conflict not only with the material arrangements of prevailing practices, but also with their underlying conventions and the social expectations of the people participating in them. As the organisation of practices determines the 'correct' performances of a practice, understanding practices requires understanding of what is perceived as 'normal' and 'acceptable' in a specific context (Aro 2016). Focusing on the experiences of participants in experimentation can illuminate the social dynamics that daily practices support and uphold and which, in turn, ensure that those practices are maintained, stabilised and reproduced - or critiqued and challenged (Davies and Doyle 2015; Hargreaves 2011; Kent 2015).

\section{Data and methods}

This article uses data collected in a home lab project in Jyväskylä in $2014 .^{2}$ The experiment was part of a city-wide Towards Resource Wisdom project that aimed to facilitate a sustainability transition in the Jyväskylä region of Finland. Experiments were used as the central means to find concrete solutions to sustainability challenges, involve and empower residents and encourage new ways of

\footnotetext{
${ }^{2}$ The 'Future Household' project was coordinated and funded by Sitra and conducted by the consulting firm D-mat Ltd and the Big Plans Bakery think tank. 40 applicants responded to a call in local newspapers and on the Internet, and five were selected in May 2014. The four-week experiment period began in October 2014. The project team was responsible for selecting the households, organising the experiments and supporting households during the project. The author was part of the team but was mainly involved in collecting data. The methodology is described in greater detail in Laakso and Lettenmeier (2016).
} 
thinking and acting (Berg et al. 2014). ${ }^{3}$ Through experimentation, the city also hoped to find ways to reduce private driving in the region: $60 \%$ of all trips are made by car and $71 \%$ of residents consider cars 'important' or 'very important' in everyday mobility (Kalenoja and Kiiskilä 2010). Mobility experiments included, for example, free public transportation days, flexible working hours for employees commuting by bus and sustainable transport education for school children.

In the project examined by this article, households conducted several trials to reduce their naturalresource use to a more sustainable level (Laakso and Lettenmeier 2016). The project built on ideas of transition management and included the steps of 1) defining a baseline and a goal for the interventions, 2) creating a specific set-up for the interventions, 3) measuring the effects of the interventions against the base line and the goal, 4) evaluating the effects against sustainability criteria, and 5) offering recommendations on how to implement the results (Laakso and Lettenmeier 2016; Luederitz et al. 2016). A central part of the project was a workshop in which households and the project team co-created ideas for experimentation. The results from the households' natural resource use were used to illustrate the resource intensity of consumption as well as the differences in scale between domains such as housing, mobility and food. ${ }^{4}$ In this way, habitual forms of consumption were also made the subject of conscious reflection (Wilk 2009). Based on the scale of impact as well as the needs and interests of the households, some of the ideas were then implemented in a four-week experiment period. After the experiment, the households and the project team, together with local actors from public and private sectors, discussed the results in a workshop to promote learning from the project.

The participants were selected on the basis of applications to represent a variety of life situations. Due to the experimental and illustrative nature of the project, and following previous initiatives (Devaney and Davies 2016; Hargreaves 2011; Hesselgren and Hasselqvist 2016), the number of households was limited to five (Table 1). The households can be described as middle-class: the participants worked in white-collar positions in, for example, schools, city administration and the private sector. In addition, the two participating students worked part-time. All participants were

\footnotetext{
${ }^{3}$ The Towards Resource Wisdom project (2013-2015) was coordinated and funded by the Finnish Innovation Fund Sitra. The concept of resource wisdom can be seen as a new method of framing sustainability as the "reasonable use of natural resources and cutting of emissions without compromising wellbeing" (Berg et al. 2014: 9). Experiments were part of the roadmap towards resource efficiency. During the project, residents of Jyväskylä were invited to submit ideas on how to reduce harmful environmental effects and improve social and economic wellbeing. A total of 212 ideas were received, of which 14 were experimented with.

${ }^{4}$ The natural resource use of households was estimated on the basis of consumption surveys and the resource intensity coefficients of each activity based on previous research (see Laakso and Lettenmeier 2016).
} 
engaged in a number of leisure time activities, from sports to culture and volunteering in local organisations.

Table 1. Description of participating households.

\begin{tabular}{|c|c|c|c|c|c|}
\hline Household & 1 & 2 & 3 & 4 & 5 \\
\hline Names & $\mathrm{Mia}^{5}$ & Noora, Niina & Olga, Olli & Pilvi, Pekka & Reetta, Risto \\
\hline Ages & 33 & 25,23 & 26,28 & 42 & 57,60 \\
\hline $\begin{array}{l}\text { Other } \\
\text { information }\end{array}$ & $\begin{array}{l}\text { Single, works } \\
\text { at three } \\
\text { different } \\
\text { locations; } \\
\text { lives in the } \\
\text { city centre. }\end{array}$ & $\begin{array}{l}\text { House-mates, } \\
\text { university } \\
\text { students; live } \\
\text { in the city } \\
\text { centre. }\end{array}$ & $\begin{array}{l}\text { Family with } \\
\text { two small } \\
\text { children; Olga } \\
\text { is on parental } \\
\text { leave and Olli } \\
\text { works in the } \\
\text { city centre; } \\
\text { live near city } \\
\text { centre. }\end{array}$ & $\begin{array}{l}\text { Family with } \\
\text { three children; } \\
\text { parents work, } \\
\text { older children } \\
\text { are at school } \\
\text { and the } \\
\text { youngest at } \\
\text { day-care; live } \\
\text { outside city } \\
\text { centre. }\end{array}$ & $\begin{array}{l}\text { Empty-nest } \\
\text { couple; live } \\
\text { outside city } \\
\text { centre; both } \\
\text { work in the } \\
\text { city centre. }\end{array}$ \\
\hline $\begin{array}{l}\text { Car } \\
\text { ownership }\end{array}$ & Owns a car & $\begin{array}{l}\text { Noora owns a } \\
\text { car }\end{array}$ & $\begin{array}{l}\text { Do not own a } \\
\text { car, but own a } \\
\text { cargo bike }\end{array}$ & Own two cars & Own two cars \\
\hline
\end{tabular}

The results from the experiment demonstrated that natural resource use could be reduced by making relatively few changes: the participating households achieved significant resource intensity reductions in mobility, food, household energy use, goods and leisure time activities, with falls of between 25 and 54 per cent (Laakso and Lettenmeier 2016). However, these reductions varied markedly between households, particularly in the case of the resource intensity of everyday mobility: while some participants managed to eliminate their private driving almost entirely and achieve reductions of up to $60 \%$, other participants could only make modest changes, despite the participatory process of selecting the trials (Laakso and Lettenmeier 2016).

\footnotetext{
${ }^{5}$ All participants have been given pseudonyms to preserve their anonymity.
} 
To analyse the reasons for these findings, this study concentrates on the trials aimed at minimising private car use, focusing on their effect on participants' mobility from the perspective of social dynamics in mobility practices. During the four-week period, the households were encouraged to replace private driving with public transportation, cycling, walking and carpooling. A car-sharing service was simulated by providing an electric car for a month for the households to book and use, and an on-demand bus service was simulated by offering a limited number of minibus rides for households with insufficient bus connections. The participants were also allowed to use their own cars if needed. In addition, Niina's and Olga's households tested the home delivery of food to aid them in their change of diet, and Reetta and Risto temporarily moved to a smaller apartment in the city centre to reduce residential energy use; these trials also had implications for mobility.

I interviewed each participant four times: 1) immediately after their selection for participation in the project, 2) prior to the experiment period, 3 ) immediately after that period and 4) six months after the project had ended. The project also featured a closed Facebook group in which the participants could share their experiences during the project and receive support and advice from other participants and the project team. The participants met three times with the project team in workshops and shared their experiences in social media and the regional news throughout the project. The consumption survey conducted both before and during the trials included a one-week report on everyday mobility: who travelled, when, where, why, how, with whom and how far. Thus, the study combines various qualitative methods to "open up new ways of understanding the ambivalent role of mobility in everyday life" (Freudendal-Pedersen et al. 2010: 25). As part of the project, I also interviewed eight local stakeholders who either participated in the final workshop or were otherwise involved in experimentation, as well as four members of the project team. These interviews serve as background information for the analysis of the context of the project itself.

The study uses the practices, rather than the individuals who perform them or the structures that surround them, as the core unit of analysis. As the trials examined in this article aimed to minimise private car use, the practice of driving is also central to the analysis. Given the interconnected nature of practices, I acknowledge the impossibility and even the inappropriateness of 'isolating' the practice of driving from the other practices that it enables or restricts or that are an inseparable part of the act of driving. As Keller et al. (2016) note, when boundary making is too clear-cut, there may even be the risk of lapsing back into addressing isolated activities. Therefore, instead, the analysis focuses on the sorts of interactions that mobility practices sustain, the role of private driving in these interactions and the ways they changed due to the experiment. 


\section{Results}

People live their lives as social beings in relation to other people, and thus they are part of many communities and tied to different roles (Butler et al. 2016; Røpke 2009). Consequently, change processes are negotiated with other people and within existing social structures and hierarchies as well as cultural and infrastructural systems (Halkier et al. 2011; Nye and Hargreaves 2010). In relation to daily mobility, this interplay proved revealing for understanding the stability and change within practices triggered by the experiment described in the previous section.

\section{Challenging the perceptions of normality}

Different meanings were associated with cars and with alternative modes of mobility by people in different social contexts. This had implications for whether particular modes of mobility were considered acceptable or even possible in these various contexts - thereby also reflecting the ways the mobility trials were experienced by the households themselves. This is illustrated by an example of Mia's experiences. Most of her colleagues had "grown up in their cars" in smaller municipalities without sufficient public transport. Thus, car use was the self-evident way to fulfil their mobility needs, even after moving away from home, which also had an effect on the selection of their future areas of residence. Private driving as the default option for being mobile thus steered other practices, such as those related to housing, which again strengthened the status of and dependence on the car. As Mia stated, "it sounded so funny to them, someone walking many kilometres to take a bus to work". Ultimately, Mia declined even to tell her colleagues that she had temporarily given up her car because it would have caused an unpleasant amount of speculation and would have placed her "in the spotlight".

For the households, as well as for many of their acquaintances, cars were important personal objects, representing not only ease of use and a way of performing a variety of geographically dispersed everyday activities, but also privacy, safety, and familiarity (see also Urry 2004). Reetta and Risto did not even attempt to give up their private driving during the experiment, even though they temporarily moved to the city centre within walking distance of their workplaces. They explained that they were "expected" to use their own cars during the working day and for business travel. However, despite having volunteered to participate in the project, which would have also justified 
changes in mobility, they admitted to not having actively questioned these expectations or discussed with their colleagues about them, which illustrates the stability of these hierarchies. This also mirrors the experiences of the other households: social expectations, conventions, values and images mutually fortify each other when understanding the correct ways to be mobile in prevailing car cultures (see also Sheller 2012). The extract below demonstrates how the symbolic value of driving acted as an obstacle to change for Reetta:

What does driving a car mean to us? It means personal freedom; that I can go anywhere I want and whenever I want. Thinking this again in a new way will be challenging. These two values are conflicting: how much I'm willing to give up the concrete freedom of coming and going and, on the other hand, how important it is for me to cut my emissions. (Reetta)

At the same time, it was completely normal for Mia to cycle to the gym, as it was already seen as "part of the exercise" and thus appropriate. In this context, the bicycle was seen as a piece of sports equipment rather than a vehicle for commuting. Moreover, Noora, Niina and Pekka stated that it was easier to justify cycling as a way to combine commuting and exercise. Nevertheless, this illustrates how, unlike driving, cycling must be explicitly justified to friends and colleagues.

Olga and Olli, in turn, had already used bicycles as their main mode of mobility. They reported having often encountered the abnormality of cycling, which reinforced their need to develop 'protective' skills and identities (see Aldred and Jungnickel 2014). They described how exhausting it sometimes was to explain their car-free lifestyle to strangers on the street or outside grocery shops. At the same time, they received peer support from the local cyclists' association, in which they were active. These experiences illustrate the marginalised role that cycling still plays in daily mobility and how important it was for the participants to find niches in which they could feel that cycling was a legitimate and recognised option.

\section{Adopting new roles in new situations}

Gaining new competences in mobility was important, as was the ability to recognise the competences to be employed in different situations. Once Pilvi and Pekka sat down to plan their weekly trips and the family tested different options for a month, they learned that it might be possible to have only one car. However, it would require an effort from all the family members to adapt to longer waiting times when travelling by bus and to the need to ask for rides from friends or friends' parents. In addition, it 
would require that these other parents were willing to drive longer trips occasionally. This was difficult for all household members at first, and Pilvi notes that for her son it was "really hard knowing that [unlike the other children's parents] his parents were not going to pick him up". For the parents, the changes required them to challenge social roles and expectations, such as those of 'being a good parent' (see also Butler et al. 2016). However, the children soon became more independent and active in organising their own lifts, thus gaining agency in their daily mobility.

For Pilvi, trialling bus use included rethinking her role as a colleague and learning a new role as a passenger (Hesselgren and Hasselqvist 2016; Laurier et al. 2008; Southerton 2013). Using the bus meant sharing the same ride with colleagues and thus having to "start the work day earlier", as they spent the bus trip discussing work concerns. Because Pilvi was obliged to be part of the work community on the bus to work, a conflict arose between practices of (social) working and those of (private) commuting. However, she soon learned that it was also acceptable to listen to music on the bus, despite sharing the trip with colleagues. Thus, she was able to alternate between social or workrelated practices and more private travel.

It was mentally demanding at first. Previously you could sit in your own car, listen to the music you wanted, or not listen to music. . . Then you step on the bus and you are not by yourself, you are in public. ... It starts already when you start walking to the bus stop, when you are by the road. Your own car was a private space. (Pilvi)

Experimenting also introduced new social situations in which the participants were unprepared to act. For example, carpooling provoked feelings of embarrassment among some participants; and eventually most of them abandoned the practice. These feelings were connected to reciprocity as a social norm and to the participants' wish to maintain their own privacy and that of others. This was considered very important, and it further strengthened their understanding of the car as a private space and as a guarantee of personal freedom. Although the experiment and the project team provided support, this support was insufficient to prepare the participants to face these emotions and take the initiative to contact and 'bother' other people, such as neighbours. As Pekka remarked, "you need to dare to call someone and agree on that. And if something comes up, you have to arrange things again: do you still try to follow what was planned, or do you have the nerve to call and tell them that something came up?" In other words, it might be necessary to trouble one's neighbour or colleague several times, and this was considered very emotionally uncomfortable. Similarly, experimenting with car-sharing among the households illustrated the participants' lack of competence in estimating 
and communicating the importance of their own needs in relation to those of others; this less concerned the ability to use online tools than the capability of negotiating and coordinating needs and desires among the participants.

\section{Navigating the various expectations of communities}

Alongside physical social groups, virtual communities have been identified as an important arena for promoting low-carbon lifestyles (Heiskanen et al. 2010). The role of social media in providing peer support also proved important in this case, illustrating how technology can change material arrangements in mobility. Noora, Niina and Mia began to use carpooling groups on Facebook to find passengers or rides, especially for longer trips. The use of applications such as Skype and WhatsApp also enabled them to maintain contact with their families without the need to physically travel. Although these applications had already been used prior to the experiment, participation in the project gave their use new meanings. Carpooling also proved different in a context created around the idea of sharing - it was considered more normal than, for example, among colleagues, as no one in Facebook groups questioned the acceptability of asking for rides (see also Aro 2016). The correct and efficient use of social media sites for carpooling and seeking rides or passengers required competence from the participants, but after they had become accustomed to it, they found sharing rides easy and fun. However, for shorter daily trips, carpooling was not as convenient, as the increased time needed for planning and travel outweighed the positive aspects. Thus, social media was an impractical tool for reorganising daily mobility; rather its use was limited to weekend and holiday trips.

I actually joined all the carpooling groups on Facebook and used them quite a lot. I always check them first. ... And now I have different groups of people for different travels, and I always ask them if they are going and usually we can share the ride. (Noora)

The experiences of the participants also reveal the contradictory expectations of experimentation. For the project team, the main goal was to achieve reductions in the households' natural-resource use and provide encouraging examples for other people; one member of the project team stated that the aim of the experiment was to demonstrate "how low you can go" in terms of natural resource use. Some of the participants admitted afterwards that they were eager to fulfil these expectations by striving to achieve the target levels of resource use despite the many difficulties this entailed. For instance, Mia reported that she was "really tired" but "gritted [her] teeth and finished what [she] had started". She 
did not use her car at all during the experiment period, but returned to driving immediately afterwards, although she also claimed to have used Facebook groups for carpooling since then.

By contrast, despite not having given up driving during the experiment, Reetta became inspired by living in a smaller apartment and began to plan a co-housing project in the city centre where residents in the whole apartment building could use shared cars. Reetta's example thus shows how car sharing can become more approachable when the context in which it is performed changes and how new meanings and skills can 'spill over' from one domain to another.

\section{Conclusions}

This study illustrates the complex, interdependent and collective organisation of (mobility) practices. The outcomes of the mobility trials in the five households depended on both the connectedness of mobility with other everyday activities and also the social dynamics in the various sites where these practices were performed. This section summarises the findings of the study and outlines some of their implications for the utilisation of experiments such as home labs in efforts to transform daily practices.

As the experiences described in the previous section illustrate, the most relevant contexts in mobility were those of home (or family), work, neighbourhood, leisure time activities and social media. Moreover, the results demonstrate how similar trials work in different ways when conducted in different contexts: for students, for example, private car ownership is seldom considered an intrinsic part of their normal standard of living, whereas in some work communities the use of a car is selfevident and unquestionable - unless alternative forms of mobility are explicitly justified in terms of exercise or activism. Moreover, awareness is required of the context of the experimentation itself and the expectations set by the project in question (see also Heiskanen et al. 2018). If the aim is to reduce private driving, consideration should be given to how the project could support this aim in various contexts and communities, rather than focusing solely on the reductions themselves and how they could be maximised.

However, contexts and life situations change, and these changes often have implications for daily mobility. As the results illustrate, experiments can act as 'windows of opportunity' by enabling 
households to deliberate on their mobility routines from a new perspective, challenge the prevailing standards and experiment with alternative solutions (see also Laakso 2017b). The participants in the five households became more skilful at and committed to changing their everyday lives, as the experiments provided not only new competences, such as the ability to use public transport or engage in carpooling, but also new understandings and reflexivity related to sustainability and what a change in lifestyle would look like. This is valuable, as people are often unaware of the environmental effects of their consumption, which constitutes a barrier to the inclusion of environmental considerations in practices (Røpke 2009). Although the changes in mobility practices were in some cases temporary, the new competences enabled the participants to question, for example, car use when their housing situation changed, as the linkages and conflicts between practices had been revealed and opened for valuation.

In addition to the 'mobility burden' imposed by the spatial and temporal characteristics of visiting friends or relatives, being at work, going to school, and so forth (Shove and Walker 2010), groupspecific expectations created an additional obstacle to changing mobility practices: being a pioneer of sustainable mobility proved socially challenging in many situations. Even though the participants in this study were keen to test new ways of being mobile and the project team was there to provide tools and help, the project community and its support (or even pressure) was insufficient to allow the participants to risk losing the 'approval' of other people in their everyday contexts. Instead of challenging social expectations, it was sometimes easier simply to be "ordinary and just do the normal thing" (Aro 2016: 122).

As people actively partake in the formation of collective assumptions on the successful performance of mobility practices, deviating from what is considered normal in a given context may evoke negative feelings: the households reported feelings of embarrassment, shame and discomfort related to, for example, car sharing, and cyclists felt they were constantly required to justify their marginalised way of being mobile. As home labs often aim to serve as positive and encouraging examples of more sustainable everyday life, these negative experiences might easily be left unnoticed (cf. Laakso 2017c). On the other hand, the participants discussed their changed mobility practices in their workplaces, and they also had empowering experiences, such as gaining new competences in bus use and social interaction during bus trips. These daily negotiations about normality and acceptability, or the 'micro-politics of practice', are valuable for considering broader questions of governance and how practices can, or should, be shaped through interventions (Davies and Doyle 2015; Nye and Hargreaves 2010; Røpke 2009). 
Experiments can thus sow the 'seeds of change' in communities (despite the experience of conflict), as home lab participants showcase alternative practices and question prevailing normalities. Nevertheless, home labs should not direct responsibility for the diffusion of practices solely to the individual participants; rather, they should focus on addressing underlying social norms, rules and cultural conventions and providing knowledge of the ways practices are experienced by people and the interactions and identities that these practices sustain. Communities are becoming ever more important in co-creating and co-operating mobility and other services (Mont and Heiskanen 2015) such as car-sharing, carpooling and co-housing, particularly in in small towns and municipalities, which face difficulties in organising profitable public transport services. Thus, it is increasingly important to identify the competences necessary for navigating contradictory norms, standards and desires and to expose insufficient technologies or other elements underpinning stability or change in a given practice.

Home labs might reveal shifts in practices or identify the elements preventing them from changing, thereby addressing the observed lack of knowledge in this field (see Shove and Walker 2010; Spurling and McMeekin 2015). The small number of households in this project enabled an in-depth, ethnographic study on the participants' experiences; as in other similar studies, the aim is not to 'confirm universal truths' but rather to learn about a phenomenon — in this case, daily mobility and its social dynamics (Flyvbjerg 2001). However, more attention should be paid to engaging people in different life situations, including those belonging to more marginalised groups. The practice approach employed in the study also revealed that reductions in resource use are not straightforward. For instance, when children receive lifts from other parents, this merely shifts the environmental impact from one participant to another. Moreover, reducing private driving might require changes in, for example, housing and the meanings related to a sense of community. A qualitative analysis of practices can thus complement quantitative approaches based on the environmental impacts of everyday life (Laakso 2017c).

These findings are also a reminder that experimentation is not an all-powerful solution for achieving sustainable lifestyles and that the sustainability goal cannot be achieved solely through isolated interventions. Rather, there is a need to go beyond the boundaries of consumption domains. Driving is rarely 'just driving'; it is a practice connecting other everyday practices, such as working, being a supportive and active parent, meeting with family or spending leisure time outside work. Changes in practices occur hand in hand with shifts in the infrastructures, institutional arrangements and cultural 
conventions that reconfigure collective practice (McMeekin and Southerton 2012). There is a need to change mobility practices not only within households but also in communities such as schools, workplaces and municipalities (see Heiskanen et al. 2015; Nye and Hargreaves 2010). Obviously, the practices an individual actually encounters and has access to are also important (Røpke 2009), and more attention should be paid to interlinked service-production and consumption practices. Finding ways to collectively critique and challenge the social dynamics that maintain daily practices might help to shift the normalities of daily mobility.

\section{Acknowledgements}

The author would like to thank the anonymous reviewers for their in-depth comments and constructive suggestions, which helped to improve the quality of the article considerably. The author would also like to thank the Finnish Innovation Fund Sitra for funding the project 'Future Household' during which the study was conducted.

\section{Declaration of Conflicting Interests}

The author declares no potential conflicts of interest with respect to the research or publication of this article.

\section{Funding}

The author would like to acknowledge the financial support of the University of Helsinki doctoral programme in interdisciplinary environmental sciences (DENVI) and of the ENERGISE project funded by the European Union's H2020 Research and Innovation programme under grant agreement number 727642 . The sole responsibility for the content of this paper lies with the author.

\section{References}

Ahonen, S., 2011. Experiences on projects promoting sustainable lifestyles in Nordic countries. TemaNord 507: Copenhagen.

Aldred, R. \& Jungnickel, K., 2014. Why culture matters for transport policy: the case of cycling in the UK. Journal of Transport Geography, 34, 78-87.

Arnott, B. et al., 2014. Efficacy of behavioural interventions for transport behaviour change: systematic review, meta-analysis and intervention coding. International Journal of Behavioral Nutrition and Physical Activity, 11(133), 1-23. 
Aro, R., 2016. Normality against Sustainability - Mobility practices of well-to-do households. Environmental Policy and Governance, 26(2), 116-128.

Bellotti, E. \& Mora, E., 2016. Networks of practices in critical consumption. Journal of Consumer Culture, 16(3), 718-760.

Berg, A., Hildén, M. \& Lahti, K., 2014. Kohti kokeilukulttuuria. Sitra: Helsinki.

Bergvall-Kåreborn, B. et al., 2009. A Milieu for Innovation - Defining Living Labs. The Proceedings of the 2nd ISPIM Innovation Symposium, New York City, USA, 6-9 December 2009.

Birtchnell, T., 2012. Elites, elements and events: Practice theory and scale. Journal of Transport Geography, 24, 497-502.

Bulkeley, H. \& Castán Broto, V., 2013. Government by experiment? Global cities and the governing of climate change. Transactions of the Institute of British Geographers, 38(3), 361375.

Butler, C., Parkhill, K.A. \& Pidgeon, N.F., 2016. Energy consumption and everyday life: Choice, values and agency through a practice theoretical lens. Journal of Consumer Culture, 16(3), 887907.

Cairns, S. et al., 2014. Sociological perspectives on travel and mobilities: A review. Transportation Research Part A: Policy and Practice, 63, 107-117.

Cass, N. \& Faulconbridge, J., 2016. Commuting practices: New insights into modal shift from theories of social practice. Transport Policy, 45, 1-14.

Davies, A.R. \& Doyle, R., 2015. Transforming Household Consumption: From Backcasting to HomeLabs Experiments. Annals of the Association of American Geographers, 105(2), 425-436.

Devaney, L. \& Davies, A.R., 2017. Disrupting household food consumption through experimental HomeLabs: Outcomes, connections, contexts. Journal of Consumer Culture, 17(3), 823-844.

Evans, D., McMeekin, A. \& Southerton, D., 2012. Sustainable Consumption, Behaviour Change Policies and Theories of Practice. In A. Warde \& D. Southerton, eds. The Habits of Consumption. Studies across Disciplines in the Humanities and Social Sciences 12. Helsinki: Helsinki Collegium for Advanced Studies, 113-129.

Evans, J. \& Karvonen, A., 2014. "Give Me a Laboratory and I Will Lower Your Carbon Footprint!” - Urban Laboratories and the Governance of Low-Carbon Futures. International Journal of Urban and Regional Research, 38(2), 413-430.

Flyvbjerg, B., 2001. Making Social Science Matter - Why social inquiry fails and how it can succeed again, Cambridge: Cambridge University Press. 
Freudendal-Pedersen, M., Hartmann-Petersen, K. \& Drewes Nielsen, L., 2010. Mixing Methods in the Search for Mobile Complexity. In B. Fincham, M. McGuinness, \& L. Murray, eds. Mobile Methodologies. Chippenham and Eastbourne: Palgrave Macmillan, 25-42.

Graham-Rowe, E. et al., 2011. Can we reduce car use and, if so, how? A review of available evidence. Transportation Research Part A: Policy and Practice, 45(5), 401-418.

Gram-Hanssen, K., 2011. Understanding change and continuity in residential energy consumption. Journal of Consumer Culture, 11, 61-78.

Halkier, B. \& Jensen, I., 2011. Methodological challenges in using practice theory in consumption research. Examples from a study on handling nutritional contestations of food consumption. Journal of Consumer Culture, 11(1), 101-123.

Halkier, B., Katz-Gerro, T. \& Martens, L., 2011. Applying practice theory to the study of consumption: Theoretical and methodological considerations. Journal of Consumer Culture, 11(1), 3-13.

Hargreaves, T., 2011. Practice-ing behaviour change: Applying social practice theory to proenvironmental behaviour change. Journal of Consumer Culture, 11(1), 79-99.

Hargreaves, T. et al., 2015. Smart homes, control and energy management: How do smart home technologies influence control over energy use and domestic life? European Council for an Energy Efficient Economy (ECEEE) 2015 Summer Study on Energy Efficiency, 1021-1032.

Heiskanen, E. et al., 2015. The local community as a "low-carbon lab": Promises and perils. Environmental Innovation and Societal Transitions, 14, 149-164.

Heiskanen, E., Hyvönen, K., Laakso, S. et al., 2017. Adoption and Use of Low-Carbon Technologies: Lessons from 100 Finnish Pilot Studies, Field Experiments and Demonstrations. Sustainability, 9(847).

Heiskanen, E., Laakso, S., Matschoss, K., Backhaus, J., Goggins, G., \& Vadovics, E., 2018. Designing real-world laboratories for the reduction of residential energy use: Articulating theories of change. GAIA, 27(S1), 60-67.

Heiskanen, E., Johnson, M. \& Vadovics, E., 2013. Learning about and involving users in energy saving on the local level. Journal of Cleaner Production, 48, 241-249.

Heisserer, B. \& Rau, H., 2015. Capturing the consumption of distance? From practice theory to the empirical investigation of everyday travel. Journal of Consumer Culture, 1-21.

Hesselgren, M. \& Hasselqvist, H., 2016. Give car-free life a try: Designing seeds for changed practices. In Proceedings of DRS 2016, Design Research Society 50th Anniversary Conference. Brighton, UK, 27-30 June 2016. 
Hesselgren, M., Hasselqvist, H. \& Eriksson, E., 2015. A car-free year: providing vehicles for change. Nordes 2015: Design Ecologies, 1-4.

Hoffmann, M.J., 2011. Climate Governance at the Crossroads: Experimenting with a Global Response after Kyoto, Oxford: Oxford University Press.

Hui, A., 2013. Moving with practices: The discontinuous, rhythmic and material mobilities of leisure. Social and Cultural Geography, 14(8), 888-908.

Hui, A., 2012. Things in motion, things in practices: How mobile practice networks facilitate the travel and use of leisure objects. Journal of Consumer Culture, 12(2), 195-215.

Irvine, K.N. \& Kaplan, S., 2001. Coping with change: The small experiment as a strategic approach to environmental sustainability. Environmental Management, 28(6), 713-725.

Kalenoja, H. \& Kiiskilä, K., 2010. Jyväskylän seudun liikennetutkimus 2009, yhteenvetoraportti: Liikenteen nykytila Jyväskylän seudulla.

Kent, J.L., 2015. Still Feeling the Car - The Role of Comfort in Sustaining Private Car Use. Mobilities, 10(5), 726-747.

Kent, J.L. \& Dowling, R., 2013. Puncturing automobility? Carsharing practices. Journal of Transport Geography, 32, 86-92.

Laakso, S., 2017a. Creating New Food Practices: A Case Study on Leftover Lunch Service. Food, Culture \& Society, 20(4), 631-650

Laakso, S., 2017b. Giving up cars - The impact of a mobility experiment on carbon emissions and everyday routines. Journal of Cleaner Production, 169, 135-142.

Laakso, S., 2017c. A practice approach to experimental governance. Experiences from the intersection of everyday life and local experimentation. Doctoral dissertation, University of Helsinki.

Laakso, S. \& Lettenmeier, M., 2016. Household-level transition methodology towards sustainable material footprints. Journal of Cleaner Production, 132, 184-191.

Laakso, S., Berg, A. \& Annala, M., 2017. Dynamics of experimental governance: A meta-study of functions and uses of climate governance experiments. Journal of Cleaner Production, 169, 816.

Luederitz, C. et al., 2016. Learning through evaluation - A tentative evaluative scheme for sustainability transition experiments. Journal of Cleaner Production, 169, 61-76.

Mont, O. \& Heiskanen, E., 2015. Breaking the stalemate of sustainable consumption with industrial ecology and a circular economy. In L. A. Reisch \& J. Thøgersen, eds. Handbook of Research on Sustainable Consumption. Cheltenham: Elgar, 33-48. 
Mont, O., Neuvonen, A. \& Lähteenoja, S., 2014. Sustainable lifestyles 2050: stakeholder visions, emerging practices and future research. Journal of Cleaner Production, 63, 24-32.

Nye, M. \& Hargreaves, T., 2010. Exploring the social dynamics of proenvironmental behavior change. A Comparative Study of Intervention Processes at Home and Work. Journal of Industrial Ecology, 14(1), 137-149.

Reckwitz, A., 2002. Toward a Theory of Social Practices: A Development in Culturalist Theorizing. European Journal of Social Theory, 5(2), 243-263.

Røpke, I., 2009. Theories of practice - New inspiration for ecological economic studies on consumption. Ecological Economics, 68(10), 2490-2497.

Sheller, M., 2012. The Emergence of New Cultures in Mobility. In F. W. Geels et al., eds. Automobility in Transition? A Socio-technical Analysis of Sustainable Transport. New York: Routledge, 180-203.

Shove, E., 2010. Beyond the ABC: climate change policy and theories of social change. Environment and Planning A, 42(6), 1273-1285.

Shove, E., Pantzar, M. \& Watson, M., 2012. The Dynamics of Social Practice: Everyday Life and how it Changes, London: Sage Publications.

Shove, E. \& Walker, G., 2007. Caution! Transition ahead: policies, practice, and sustainable transition management. Environment and Planning A, 39, 763-770.

Shove, E. \& Walker, G., 2010. Governing transitions in the sustainability of everyday life. Research Policy, 39(4), 471-476.

Shove, E., Watson, M. \& Spurling, N., 2015. Conceptualizing connections: Energy demand, infrastructures and social practices. European Journal of Social Theory, 18(3), 274-287.

Southerton, D., 2013. Habits, routines and temporalities of consumption: From individual behaviours to the reproduction of everyday practices. Time \& Society, 22(3), 335-355.

Spurling, N. et al., 2013. Interventions in practice: re-framing policy approaches to consumer behaviour. Sustainable Practices Research Group.

Spurling, N. \& McMeekin, A., 2015. Interventions in practices: Sustainable mobility policies in England. In Y. Strengers \& C. Maller, eds. Social Practices, Intervention and Sustainability. Abingdon, Oxfordshire: Routledge.

Thøgersen, J. \& Møller, B., 2008. Breaking car use habits: The effectiveness of a free one-month travelcard. Transportation, 35(3), 329-345.

Urry, J., 2004. The "System” of Automobility. Theory, Culture \& Society, 21(4/5), 25-39.

Warde, A., 2005. Consumption and Theories of Practice. Journal of Consumer Culture, 5(2), 131153. 
Watson, M., 2012. How theories of practice can inform transition to a decarbonised transport system. Journal of Transport Geography, 24, 488-496.

\section{Author biography}

Senja Laakso, PhD, works as a postdoctoral researcher at the Centre for Consumer Society Research at the University of Helsinki. Her research focuses on sustainable consumption, social practices and transition paths towards sustainable food and energy systems. In her doctoral thesis, she analysed local sustainability experiments and their potential to change social practices. She is currently working on the Horizon 2020 -funded ENERGISE project as well as on 'Eating and Energy Use Reconfigured? Disruptions and Novel Transition Pathways in Food and Energy Systems (EETRANS)' project funded by the Academy of Finland. Web page: http://blogs.helsinki.fi/sglaakso/, Twitter: @SenjaLaakso. 